\title{
Hybrid Licensing of Product Innovations
}

\author{
ELISABETTA OTTOZ, FRANCO CUGNO* \\ Università di Torino
}

This paper shows that when a product innovation is protected by both patents and trade secrets, under U.S. law the innovator can be induced to license a rival even if patent protection is very broad and there are no partially competitive older products. This opportunity may benefit society. Nevertheless, some legal restrictions in force at the moment do not permit society to reap all potential gains. Since incentive and efficiency considerations suggest that a socially optimal contract should provide for both a negative fixed fee and post-patent royalties at the same unit level as before a patent's expiration, we conclude that per se probibitions of these practices are unjustified.

\section{INTRODUCTION}

In an oft-cited decision - Brulotte v. Thys Co., 379 U.S. 29 (1964) - the U.S. Supreme Court stated that a patentee's use of a royalty agreement that projects beyond the expiration date of the patent is unlawful per se, on the ground that to collect such royalties was to extend the monopoly of the patent to inventions that are properly in the public domain. The license involved in the case was limited to patents, and the royalty rate, which was based on the licensee's use of a patented machine, was the same both before and after the patent expired (Cohen and Gutterman, 1998).

Charging royalties over a period that exceeds the legal term of patent protection is in any case a lawful practice in hybrid licensing agreements - that is, when licenses tie patents to some other intellectual property rights such as trademarks or trade secrets (which have no fixed expiration). But since courts presume that, as a rule, in these hybrid licensing agreements patents are inherently more

\footnotetext{
* We wish to thank the editor and two anonymous referees for their insightful comments, as well as participants at the fourth annual SIDE Conference (University of Bologna, November 2008). Research support from MIUR, PRIN 2005, Prot. 2005130219_003 is kindly acknowledged. The usual disclaimer applies.
} 
valuable than tied intellectual property rights, contracts must provide for appropriate decreases in the royalty rates when patents terminate. The result is that it is de facto impossible to subscribe an enforceable contract providing for unchanged royalties after patent expiration: consistent with Brulotte, such a clause would be invalidated as an unfair attempt by the licensor to use the patent as leverage into the post-expiration market.

From an economics perspective, the reasoning underlying the decision in Brulotte has been roundly criticized by, among others, Gilbert and Shapiro (1997) and Judge Posner in Scheiber v. Dolby Labs, 293 F.3d 1014 (7th Cir. 2002). ${ }^{1}$ Their counter-argument is that, since the patentee can in no way extract royalties above the value of the innovation, post-expiration royalties do not extend the patent duration either technically or practically: as far as market power is concerned, it is a detail whether the patentee extracts royalties at a higher rate over a shorter period of time or at a lower rate over a longer period of time. ${ }^{2}$ Moreover, permitting royalties to be paid over a longer period can reduce the deadweight loss from the patent monopoly (Gilbert and Shapiro, 1990). Successively, Law (2004) built a model of hybrid licensing, where in an initially duopolistic market the proprietor of a process innovation, who is not a producer of the final good, is considering the prospect of licensing one or both of the producing duopolists. In this context, hybrid licensing can enhance efficiency for non-drastic innovations. ${ }^{3}$

But what can be said about a situation in which a new product enters the market and the innovator is a producer of the final good? The paper addresses this issue under the further hypotheses that the product innovation is drastic, i.e. no one would buy a possible older product (Gilbert, 2006), and the patent is very broad, in the sense that the costs of inventing a non-infringing imitation are greater than duopoly profits (Gallini, 1992).

In analyzing optimal patent design with costly imitation, Gallini (1992) finds that broad patents, with patent life adjusted to generate the desired return from research, are socially efficient in that they limit socially wasteful imitation costs. This result has been questioned on the ground that imitation costs can be

\footnotetext{
1 See also Bowman (1973), Ayres and Klemperer (1999), Landes and Posner (2003), U.S. Department of Justice and Federal Trade Commission (2007), and Devlin (2008). While labelling Justice Douglas' majority opinion as careless, Baxter (1966) argues that a prohibition against extending royalty payments beyond the patent life is justified.

${ }^{2}$ In the Guidelines on the Application of Article 81 of the EC Treaty to Technology Transfer Agreements issued in 2004, the European Commission adopted this point of view. See the concluding remark in Section 4 below.

3 A process innovation traditionally is said to be drastic (non-drastic) if the monopoly price with the new technology is below (above) the unit cost with the old technology.
} 
Hybrid Licensing of Product Innovations / 581

avoided through patent licensing (Maurer and Scotchmer, 2002): if entry by imitation constitutes a credible threat because non-infringing imitations can be obtained at positive but not prohibitive costs, the patent holder will be induced to license. If so, optimality requires long-lived, narrow patents; that is, imitation costs have to be very low, whereas the incentive to innovate is preserved through an adequate prolongation of the patent life. ${ }^{4}$

Our paper shows that when a product innovation is protected by both patents and trade secrets, under U.S. law the producer-innovator may find it in her interest to license a rival even if patent protection is very broad and there are no partially competitive older products. ${ }^{5}$ Such hybrid licensing agreements, which extend royalty payments beyond the expiration date of the patent, improve consumer's welfare with respect to the temporary monopoly alternative (like narrow, long-lived patents in the case of pure patent licensing). Nevertheless, since consumer's benefits are at a maximum when the royalty level is the same both before and after patent's expiration, not all opportunities are currently exploited: court decisions that invalidate hybrid licensing contracts with non-decreasing royalties do not permit society to reap all of the potential gains from these agreements.

Moreover, we show that in order to induce the innovator to strictly prefer a hybrid licensing agreement, although acceptable by the entrant, limited side payments (negative fixed fees) should be envisaged. This raises another matter, this time involving antitrust concerns about side payment agreements: since, in general, such agreements impose a cap on the entrant's output, thus reducing competition, they are likely to be illegal under the antitrust laws. Nevertheless, as we will see, in a hybrid licensing context it may be socially efficient to permit limited negative fees.

Section 2 contains a discussion of some legal aspects about royalty terms. In Section 3 the model is discussed and the results on efficiency and feasibility of hybrid licensing agreements are presented. Section 4 concludes.

\section{ROYALTY TERMS}

The issue of the permissible royalty term has arisen in three distinct contexts: pure patent licensing, pure secret licensing, and hybrid patent-secret licensing agreements.

\footnotetext{
4 The literature on optimal patents is very large. A selection of the first contributions includes Tandon (1982), Gilbert and Shapiro (1990), Klemperer (1990), Gallini (1992), and Denicolò (1996).

${ }^{5}$ Our model does not address the question of patentee's optimal choice of the patent-secret mix. This sort of choice is studied in Ottoz and Cugno (2008) where, however, licensing effects are not explicitly considered.
}

DOI: $10.2202 / 1555-5879.1380$ 
Pure patent licensing. When the subject matter of a license agreement is protected purely by patent law, the reference decision is that of the Supreme Court in Brulotte v. Thys Co. 379 U.S. 29 (1964). As summarized in Judge Berzon's opinion in Zila, Inc. v. Tinnell 502 F.3d 1014 (9th Cir. 2007), "...the case involved various patents held by the Thys Company, which sold farmers a hop-picking machine for a flat sum but required them to purchase a license for the patents on the machines in order to use the product. The license contract demanded that, in addition to the initial purchase price of the machines and onerous restrictions on their assignment or use, the farmers pay the larger of a $\$ 500$ annual royalty or a set royalty rate tied to the amount of hops they harvested each year. The last patent incorporated into the machines expired in 1957. When the farmers subsequently refused to pay the royalty, the Thys Company sued to enforce the licensing contract."

The Supreme Court invalidated the license agreement as "a bald attempt to exact the same terms and conditions for the period after the patents have expired as they do for the monopoly period." While conceding that ".... a patent empowers the owner to extract royalties as high as he can negotiate with the leverage of his monopoly," the Court deemed it unacceptable to use that same leverage to impose royalty payments for a time extending beyond the patent life. The Court considered the extension of the royalty obligation beyond the patent life as a sort of tying arrangement, whereby a monopolist uses its power in one market to assert itself in another market: a patentee which enjoys a monopoly in the preexpiration market cannot use that monopoly as leverage into the post-expiration market (Koenig, 2003). As a result, the Court concluded that a patentee's use of a royalty agreement that projects beyond the expiration date of the patent is unlawful per se, and held the licensee's royalty obligation unenforceable.

The economic reasoning in Brulotte has been recently challenged by Court of Appeals Judge Richard Posner in his decision on Scheiber v. Dolby, Inc., 293 F.3d 1014 (7th Cir. 2002) on the ground that "The duration of the patent fixes the limit of the patentee's power to extract royalties; it is a detail whether he extracts them at a higher rate over a shorter period of time or a lower rate over a longer period of time." Judge Posner reluctantly applied the Brulotte rule to the case at hand, but invited the Supreme Court to overrule it. However, the Supreme Court declined to review the decision in Scheiber.

Pure secret licensing. In the case of pure secret licensing, challenges to the agreement are often brought by the licensee after the trade secret has become publicly available. 
Hybrid Licensing of Product Innovations / 583

According to the decision in Pitney Bowes, Inc. v. Mestre, 701 F.2d 1365, 1373 (11th Cir. 1983), the validity of the royalty term of a pure secret license is merely a matter of contract law - that is, any term freely negotiated by the licensor and licensee is enforceable. If the parties do not stipulate when royalty payments should terminate, the court will not establish such a term but will enforce the obligation as long as the licensee uses the trade secret (Miller, 1989). Warner-Lambert v. John F. Reynolds, Inc, 178 F. Supp. 655 (S.D.N.Y. 1955) is the classic reference case in this area. In 1881, the discoverer of the secret formula for Listerine antiseptic granted Warner-Lambert's predecessor the exclusive commercial use of the formula in exchange for a royalty obligation. The contract contained no date of termination. After seventy-five years, WarnerLambert filed a declaratory judgment action to terminate the royalty payments on the ground that the Listerine formula had become public knowledge since 1931, when it had been published in the Journal of the American Medical Association. The court ruled in favor of the defendant, holding that, contrary to the case of royalty agreements involving patents, there was no public interest in preventing enforcement of a royalty obligation when the licensed trade secret becomes publicly available. The court noted that Warner-Lambert, acquiring the secret formula subject to the risk of disclosure, won and maintained a dominant position in the antiseptic market through the years. Thus, the plaintiff's obligation was intended to continue until it ceased to manufacture or sell Listerine, whether or not the formula was disclosed.

Hybrid licensing. When a license agreement involves a technology with both patented and unpatented parts, at the expiration of the patent the licensee often suspends royalty payments, while the licensor claims that know-how protected by trade secret supports the royalty obligation after the patents have expired. If the agreement does not clearly differentiate between patents and trade secrets by providing a separate royalty for each, then courts usually decide in favour of the licensee on the basis that a hybrid license cannot be used to extend the patent monopoly in contradiction of Brulotte (e.g., Chromalloy American Corp. v. Fischmann, 716 F.2d 683, 686 (9th Cir. 1983)).

This point is clarified in Pitney Bowes, Inc. v. Mestre, 701 F.2d 1365, 1373 (11th Cir. 1983). The case concerned a licensing contract for a paper-collating machine in which the licensee agreed to pay royalties to the inventor for the right to manufacture and market the machine. In examining the case, "...the district court agreed with Mestre and Pitney Bowes that the agreement licensed both patent rights and trade secrets and thus was a 'hybrid' agreement." Despite this

DOI: $10.2202 / 1555-5879.1380$ 
finding, the district court concluded that, based on Brulotte, the agreement expired when the last patent on the machine expired (Gates and Maier, 2009).

On appeal, the licensor contended "...that the district court should not have applied Brulotte and that Brulotte is distinguishable on the ground that the royalty payments in that case were solely for patent rights," while the agreement in question licensed both patent rights and trade secrets. The court rejected this claim on the ground that, first, as in Brulotte, "...the exclusive rights granted under the license agreement applied equally before and after the patents' expiration" and, second, the agreement required the licensee "...to pay royalties at the same rate and on the same basis after the patents expired that it paid while the patent was in effect." Nevertheless, citing Brulotte, the court observes that "...if a patent owner can prove that he did not use his patent monopoly leverage to exact reduced post-expiration trade secret payments..." then a hybrid licensing agreement that provides for a step-down in royalty rate after the patent expires would be enforceable.

As Gates and Maier (2009) point out, following Pitney Bowes other courts have continued to hold that hybrid licensing agreements providing for "level royalties" - that is, royalties which do not diminish after patent's expiration - are unenforceable. ${ }^{6}$ Thus, hybrid licenses should include provisions that separate royalties from different intellectual property rights - such as royalties from patents and those from the use of trade secrets - and eliminate royalties from patents that expire or are invalidated - which stand for the proposition that royalties should not be due on patents upon expiration or invalidation (Jones et al., 2007).

\section{HYBRID LICENSING VS. TEMPORARY MONOPOLY EXPLOITATION}

In this section we present a simple model where a proprietary product is protected by both patent and trade secret. First, we show that even if the patent is very broad, the technology holder may be indifferent between temporarily exploiting monopoly power and licensing to a rival the entire technology from the outset through a hybrid license. The second option would be better for consumers and thus socially superior. Then, we point out that if limited negative fixed fees are allowed, a feasible hybrid licensing agreement that benefits consumers may become the technology holder's preferred choice.

\footnotetext{
${ }^{6}$ See, e.g., Boggild v. Kenner Products, 776 F.2d 1315 (6th Cir.1985); Baladvon Inc. v Abbott Labs., 871 F. Supp. 89, 97 (D Mass. 1994); Sanford Redmond, Inc. v Mid-America Dairymen, Inc., 29 USPQ 2d (BNA) 1222, 1226 (SDNY 1992).
} 
Hybrid Licensing of Product Innovations / 585

\subsection{THE MODEL}

Let's consider a firm able to produce a new good by utilizing a technology jointly protected by patent and trade secret. By assumption, a trade secret extends beyond the statutory life of the patent, which is meant to have maximum breadth, so that imitation is necessarily infringing.

There is only one potential entrant who, when the patent expires, can enter the market bearing a fixed cost of independent invention of the secret or through a license. (We will consider the case of numerous potential entrants in Subsection 3.4 below.) The purchase of the license is preferred if the royalty per unit of product set in the contract is not higher than $\bar{\rho}_{s}$. A third opportunity is that the two firms agree from the outset on a hybrid license allowing the immediate entry of the licensee, despite the maximum patent's breadth, conditional on the payment of a royalty per unit output $\rho_{p}$ during the patent life and a subsequent royalty $\rho_{s}$ after patent's expiration.

The price of the good and the quantity produced are respectively $P$ and $X$ and the inverse demand function is $P=a-X$. Let's assume then that unit production cost is constant and set equal to zero. The two firms compete à la Cournot - that is, each firm chooses a quantity to produce that maximizes its profits, given an equilibrium expectation about the other firm's output. Then, calling $X_{p}^{A}$ and $X_{s}^{A}$ the production flows of the proprietary firm before and after patent's expiration, and $X_{p}^{B}$ and $X_{s}^{B}$ the production flows of the entrant firm, in the case of a hybrid license we have

$$
X_{i}^{A}=\frac{a+\rho_{i}}{3}, \quad X_{i}^{B}=\frac{a-2 \rho_{i}}{3}, \quad P_{i}=\frac{a+\rho_{i}}{3}, \quad i=p, s,
$$

where the $X_{i}^{A}$ 's values maximize the profit flows $\Pi_{i}^{A}=P_{i} X_{i}^{A}+\rho_{i} X_{i}^{B}$ given the equilibrium expectations of $X_{i}^{B}$, while the $X_{i}^{B}$ 's values maximize the profit flows $\Pi_{i}^{A}=P_{i} X_{i}^{B}-\rho_{i} X_{i}^{B}$ given the equilibrium expectations of $X_{i}^{A}$.

The corresponding profit flows, $\Pi_{i}^{A}$ and $\Pi_{i}^{B}$ will be

(2) $\Pi_{i}^{A}=\left(\frac{a+\rho_{i}}{3}\right)^{2}+\rho_{i} \frac{a-2 \rho_{i}}{3}, \quad \Pi_{i}^{B}=\left(\frac{a-2 \rho_{i}}{3}\right)^{2}, \quad i=p, s$,

DOI: $10.2202 / 1555-5879.1380$ 
while the flows of consumer's surplus, $C S_{i}=\left(a-P_{i}\right)\left(X_{i}^{A}+X_{i}^{B}\right) / 2$, is given by

$$
C S_{i}=\frac{1}{2}\left(\frac{2 a-\rho_{i}}{3}\right)^{2}, \quad i=p, s .
$$

Let's now indicate with $\tau$ the patent's length and suppose, without loss of generality, that secret duration is infinite. Then, setting $T=1-e^{-r \tau}$, where $r$ is the discount rate, by using equation (2) we can write the present values of the two firms' profits as

(4) $V^{A}=\frac{T}{r}\left[\left(\frac{a+\rho_{p}}{3}\right)^{2}+\rho_{p} \frac{a-2 \rho_{p}}{3}\right]+\frac{1-T}{r}\left[\left(\frac{a+\rho_{s}}{3}\right)^{2}+\rho_{s} \frac{a-2 \rho_{s}}{3}\right]$,

$$
V^{B}=\frac{T}{r}\left(\frac{a-2 \rho_{p}}{3}\right)^{2}+\frac{1-T}{r}\left(\frac{a-2 \rho_{s}}{3}\right)^{2} .
$$

Next, from equation (3) we obtain the present value of consumer's surplus, that is

$$
W=\frac{1}{2}\left[\frac{T}{r}\left(\frac{2 a-\rho_{p}}{3}\right)^{2}+\frac{1-T}{r}\left(\frac{2 a-\rho_{s}}{3}\right)^{2}\right] .
$$

\subsection{SOCIAL EFFICIENCY}

Equations (4), (5) and (6) encompass the case of entry of the rival firm after patent's expiration by the means of a pure secret license. This case is obtained by setting $\rho_{p}=a / 2$ (implying $X_{p}^{B}=0$ ) and $\rho_{s}=\bar{\rho}_{s} \cdot{ }^{7}$ Thus, if $\bar{V}^{A}$ and $\bar{V}^{B}$ stand for the present values of the two firms' profits under pure secret licensing,

$$
\bar{V}^{A}=\frac{T}{r}\left(\frac{a}{2}\right)^{2}+\frac{1-T}{r}\left[\left(\frac{a+\bar{\rho}_{s}}{3}\right)^{2}+\bar{\rho}_{s} \frac{a-2 \bar{\rho}_{s}}{3}\right],
$$

\footnotetext{
${ }^{7}$ Obviously, $X_{p}^{B}=0$ for all $\rho_{p} \geq a / 2$.
} 
Hybrid Licensing of Product Innovations / 587

$$
\bar{V}^{B}=\frac{1-T}{r}\left(\frac{a-2 \bar{\rho}_{s}}{3}\right)^{2}
$$

Analogously, if $\bar{W}$ stands for the present value of consumer's surplus,

(9) $\bar{W}=\frac{1}{2}\left[\frac{T}{r}\left(\frac{a}{2}\right)^{2}+\frac{1-T}{r}\left(\frac{2 a-\bar{\rho}_{s}}{3}\right)^{2}\right]$.

By comparing equations (4) and (5) with equations (7) and (8), we can now show that there exists a set of hybrid licensing agreements, each characterized by a pair of royalty rates $\left(\rho_{p}, \rho_{s}\right)$, which leave the two firms with the same present values of profits as a pure secret license released after the patent's expiration.

Proposition 1. There exists a set of pairs $\left(\rho_{p}, \rho_{s}\right)$ such that a bybrid license is equally profitable for both firms as a pure secret license.

Proof. By setting $V^{B}=\bar{V}^{B}$ (equations (5) and (8)), we have

$$
\left(\frac{a-2 \rho_{p}}{3}\right)^{2}=\frac{1-T}{T}\left[\left(\frac{a-2 \bar{\rho}_{s}}{3}\right)^{2}-\left(\frac{a-\rho_{s}}{3}\right)^{2}\right]
$$

This equation gives us the pairs $\left(\rho_{p}, \rho_{s}\right)$ that make hybrid licensing as profitable as pure secret licensing for the entrant firm. Solving for $\rho_{p}$,

$$
\rho_{p}=\frac{a}{2} \pm \frac{1}{2} \sqrt{\frac{1-T}{T}\left[\left(a-2 \bar{\rho}_{s}\right)^{2}-\left(a-2 \rho_{s}\right)^{2}\right]} .
$$

The pairs $\left(\rho_{p}, \rho_{s}\right)$ associated with the positive sign have to be discarded because in this case $\rho_{p}>a / 2$ for $\rho_{s}>\bar{\rho}_{s}$, a meaningless result in this context. Thus, if we indicate with $\left(\hat{\rho}_{p}, \hat{\rho}_{s}\right)$ the pairs $\left(\rho_{p}, \rho_{s}\right)$ having the required property, we can write

DOI: $10.2202 / 1555-5879.1380$ 


$$
\hat{\rho}_{p}=\frac{a}{2}-\frac{1}{2} \sqrt{\frac{1-T}{T}\left[\left(a-2 \bar{\rho}_{s}\right)^{2}-\left(a-2 \hat{\rho}_{s}\right)^{2}\right]} .
$$

Analogously, by setting $V^{A}=\bar{V}^{A}$ (equations (4) and (7)), we have

$$
\begin{aligned}
& \left(\frac{a+\rho_{p}}{3}\right)^{2}+\rho_{p} \frac{a-2 \rho_{p}}{3}-\left(\frac{a}{2}\right)^{2}= \\
= & \frac{1-T}{T}\left[\left(\frac{a+\bar{\rho}_{s}}{3}\right)^{2}+\bar{\rho}_{s} \frac{a-2 \bar{\rho}_{s}}{3}-\left(\frac{a+\rho_{s}}{3}\right)^{2}-\rho_{s} \frac{a-2 \rho_{s}}{3}\right],
\end{aligned}
$$

from which we obtain the pairs $\left(\rho_{p}, \rho_{s}\right)$ that make hybrid licensing as profitable as pure secret licensing for the technology proprietor firm. By solving for $\rho_{p}$ we again obtain equation (11).

Summing up, all hybrid licensing agreements that respect condition (12) are equally profitable for both firms and are equally profitable as compared to a pure secret license.

We now see the effects on consumer's surplus. By operating on equations (6) and (12) we can show that each hybrid licensing agreement characterized by a pair $\left(\hat{\rho}_{p}, \hat{\rho}_{s}\right)$ implies a present value of the consumer's surplus higher than that associated with a pure secret licensing agreement.

Proposition 2. A bybrid license implying the same profitability as a pure secret license is preferable for consumers.

Proof. Let us set $\rho_{p}=\hat{\rho}_{p}$ and $\rho_{s}=\hat{\rho}_{s}$. Then, differentiating consumer's surplus in equation (6) and the condition of equal profitability in equation (12), both with respect to $\rho_{s}=\hat{\rho}_{s}$, we obtain

(14) $\frac{d W}{d \hat{\rho}_{s}}=-\frac{T}{r} \frac{2 a-\hat{\rho}_{p}}{9} \frac{d \hat{\rho}_{p}}{d \hat{\rho}_{s}}-\frac{1-T}{r} \frac{2 a-\hat{\rho}_{s}}{9}, \frac{d \hat{\rho}_{p}}{d \hat{\rho}_{s}}=-\frac{1-T}{T} \frac{a-2 \hat{\rho}_{s}}{a-2 \hat{\rho}_{p}}$, that is, by substituting, 
Hybrid Licensing of Product Innovations / 589

$$
\frac{d W}{d \hat{\rho}_{s}}=\frac{1-T}{r} \frac{\left(2 a-\hat{\rho}_{p}\right)\left(a-2 \hat{\rho}_{s}\right)-\left(2 a-\hat{\rho}_{s}\right)\left(a-2 \hat{\rho}_{p}\right)}{9\left(a-2 \hat{\rho}_{p}\right)}
$$

Now, it is easy to verify that $\hat{\rho}_{p} \geq \hat{\rho}_{s}$ implies $d W / d \hat{\rho}_{s} \geq 0$. Hence starting from a situation where $\rho_{s}=\bar{\rho}_{s}$ and $\rho_{p}=a / 2$ (pure secret license), it is possible to increase consumer's surplus without reducing firms' profitability, by shifting to a hybrid license, implying a reduction in $\rho_{p}$ coupled with an adequate increase in $\rho_{s}$.

Since $d W / d \hat{\rho}_{s}>0$ as long as $\hat{\rho}_{p}>\hat{\rho}_{s}$, it immediately follows that a hybrid license implying $\hat{\rho}_{p}=\hat{\rho}_{s}$ maximizes consumer's surplus subject to $V^{A}=\bar{V}^{A}$ and $V^{B}=\bar{V}^{B}$. Then, the following proposition holds.

Proposition 3. The legal probibition against entering a bybrid licensing agreement providing for the same royalty before and after patent's expiration is socially inefficient.

Anyway, as asserted in Proposition 2, in our model hybrid licensing agreements improve social welfare even if per unit royalties must decline after patent expiration. This welfare improvement is due to the fact that if hybrid licensing agreements were not feasible, the royalties would be $\rho_{p}=a / 2$ (which would imply monopolistic exploitation of the patent) and $\rho_{s}=\bar{\rho}_{s}$, while hybrid licenses permit a lesser difference between $\rho_{p}$ and $\rho_{s}$, and this smoothing favours consumers. In other words, allowing for the immediate entry of the rival firm in spite of the drastic nature of the innovation, hybrid licensing during the patent life benefits consumers more than it will damage them successively.

\subsection{INCENTIVES TO ADOPT HYBRID LICENSING}

Thus far we have seen that the present value of consumer's surplus is higher if royalties $\rho_{P}$ and $\rho_{s}$ are chosen according to condition (12), as compared to the case of a pure secret license, while the present values of profits accruing to both the innovator and the entrant remain unaltered. Obviously, this means that the innovator will be indifferent between offering a hybrid license from the outset

DOI: $10.2202 / 1555-5879.1380$ 
and offering a pure secret license in the future while retaining the monopoly privilege during the patent life. That is, in this case the innovator has no compelling reason to offer a hybrid license. The following proposition shows how the possibility of including in the contract a clause providing for a side payment would induce the licensor to strictly prefer hybrid licensing. If this side payment is limited, consumers continue to benefit from the agreement.

Proposition 4. If licensing agreements providing for negative fixed fees are feasible, it is possible to obtain, in comparison with a pure secret license, an increase in the present value of both consumer's surplus and licensor's profits.

Proof. By setting $W=\bar{W}$ (equations (6) and (9)), we have

$$
\left(\frac{2 a-\rho_{p}}{3}\right)^{2}-\left(\frac{a}{2}\right)^{2}=\frac{1-T}{T}\left[\left(\frac{2 a-\bar{\rho}_{s}}{3}\right)^{2}-\left(\frac{2 a-\rho_{s}}{3}\right)^{2}\right],
$$

from which we can obtain the pairs $\left(\tilde{\rho}_{p}, \tilde{\rho}_{s}\right)$ leaving consumers indifferent between a hybrid license and a pure secret license, given by ${ }^{8}$

$$
\tilde{\rho}_{p}=2 a-\frac{1}{2} \sqrt{9 a^{2}+4 \frac{1-T}{T}\left[\left(2 a-\bar{\rho}_{s}\right)^{2}-\left(2 a-\tilde{\rho}_{s}\right)^{2}\right]} .
$$

Let us set $\rho_{p}=\tilde{\rho}_{p}$ and $\rho_{s}=\tilde{\rho}_{s}$ in equation (4). Then, differentiating licensor's profits in equation (4) and the condition in equation (17), both with respect to $\tilde{\rho}_{s}$, we have

(18) $\frac{d V^{A}}{d \tilde{\rho}_{s}}=\frac{T}{r} \frac{5\left(a-2 \tilde{\rho}_{p}\right)}{9} \frac{d \tilde{\rho}_{p}}{d \tilde{\rho}_{s}}+\frac{1-T}{r} \frac{5\left(a-2 \tilde{\rho}_{s}\right)}{9}, \frac{d \tilde{\rho}_{p}}{d \rho_{s}}=-\frac{1-T}{T} \frac{2 a-\tilde{\rho}_{s}}{2 a-\tilde{\rho}_{p}}$,

that is

$$
\frac{d V^{A}}{d \tilde{\rho}_{s}}=\frac{1-T}{r} \frac{5\left(a-2 \tilde{\rho}_{s}\right)\left(2 a-\tilde{\rho}_{p}\right)-5\left(a-2 \tilde{\rho}_{p}\right)\left(2 a-\tilde{\rho}_{s}\right)}{9\left(2 a-\tilde{\rho}_{p}\right)} .
$$

\footnotetext{
8 As for the case in Proposition 1, the pairs $\left(\rho_{p}, \rho_{s}\right)$ associated with a positive sign have to be discarded.
} 
Hybrid Licensing of Product Innovations / 591

At this point, we can easily verify that $\tilde{\rho}_{p}>\tilde{\rho}_{s}$ implies $d V^{A} / d \tilde{\rho}_{s}>0$. Thus, starting from a situation where $\rho_{s}=\bar{\rho}_{s}$ and $\rho_{p}=a / 2$ (pure secret license), it is possible to increase licensor's profits without reducing consumer's surplus by shifting to a hybrid license, implying a reduction in $\rho_{p}$ coupled with an adequate increase in $\rho_{s}$. Since a royalty contract $\left(\tilde{\rho}_{p}, \tilde{\rho}_{s}\right)$ increases licensor's profits with respect to a pure secret license, whereas a contract $\left(\hat{\rho}_{p}, \hat{\rho}_{s}\right)$ leaves them unchanged, when $\tilde{\rho}_{s}=\hat{\rho}_{s}$ we must have $\tilde{\rho}_{p}>\hat{\rho}_{p}$.

Let's then set $\tilde{\rho}_{s}=\hat{\rho}_{s}$ and suppose a $\rho_{p}$ is chosen such that $\hat{\rho}_{p}<\rho_{p}<\tilde{\rho}_{p}$. This licensing agreement implies, as compared to the pure secret license, higher present values of consumer's surplus and licensor's profits and a lower present value of entrant's profits, which represents a violation of the participation constraint. If the benefits to the technology proprietor firm outweigh the losses of the entrant, however, the participation constraint may be satisfied with a lump-sum transfer from the licensor to the licensee.

Partially differentiating $V^{A}$ and $V^{B}$ with respect to $\rho_{p}$, we obtain

$$
\frac{\partial V^{A}}{\partial \rho_{p}}=T \frac{2\left(a+\rho_{p}\right)}{9}+T \frac{a-4 \rho_{p}}{3}, \quad \frac{\partial V^{B}}{\partial \rho_{p}}=-T \frac{2\left(a-2 \rho_{p}\right)}{9},
$$

and it is easy to verify that for $\rho_{p}<a / 2$ we have $\partial V^{A} / \partial \rho_{p}+\partial V^{B} / \partial \rho_{p}>0$, so that the required transfer is feasible.

As has been widely recognized, permitting negative fixed fees in licensing contracts can be somewhat dangerous. If side payments of this kind are allowed, a licensing contract may become the equivalent of a bribe paid by the licensor to induce the potential entrant to stay out of the market (Shapiro, 1985). ${ }^{9}$ Outside a patent settlement context in which the parties aim to avoid litigation costs for alleged infringement, such a payment would always appear to be

\footnotetext{
${ }^{9}$ In our framework, this extreme outcome would be obtained with a contract envisaging royalties $\rho_{p}, \rho_{s} \geq a / 2$, so that $X_{p}^{B}=X_{s}^{B}=0$, and a negative fixed fee high enough to compensate the potential entrant for giving up entry through independent invention of secrets after patent's expiration.
}

DOI: $10.2202 / 1555-5879.1380$ 
harmful for consumers and thus blatantly unlawful under the antitrust laws (Lemley and Shapiro, 2005): a monopolist is not allowed to pay a potential entrant to stay off the market or to pay a rival to reduce its output. On the other hand, in a hybrid licensing context-side payments do not necessarily result in anticompetitive effects. Provided negative fees and royalties per unit output are not too high, they can make privately convenient licensing agreements that enhance consumers' welfare. Thus, even outside the patent settlement context, negative fixed fees should not be per se illegal under the antitrust law: reasoned case-bycase decisions seem to be the best course.

\subsection{NuMEROUS POTENTIAL ENTRANTS}

The extension to the case of $n>1$ identical and identified potential entrants is a straightforward exercise which adds nothing relevant to the topic addressed in this paper. In effect, in this case the technology proprietor is able to sign licenses with all industry participants providing for adequate royalties before and after patent expiration. Then, it is easy to show that equations from (10) to (15) continue to hold, keeping unaltered our results on both the feasibility and efficiency of hybrid licensing.

If from the very beginning not all potential entrants are identified, however, a hybrid licensing agreement may be unfeasible. Since a hybrid license has to fix a post-expiration royalty greater than that which reflects the trade secret value, hybrid license assignees would take the risk of becoming uncompetitive with respect to the as-yet unidentified entrants through pure secret licenses or independent invention of secrets. Therefore, our conclusions are limited to the case in which the patentee is able to sign licenses with most or all industry participants and there are some barriers to entry to prevent new firms from taking over the market after the patent expires (Gilbert and Shapiro, 1997).

\section{CONCLUDING REMARKS}

This paper shows that when a product innovation is protected by both patents and trade secrets, under the U.S. law the innovator can be induced to license a rival even if patent protection is very broad and there are no partially competitive older products. These hybrid licensing agreements, which extend royalty payments beyond the expiration date of the patent, can benefit consumers with respect to the temporary monopoly alternative. Nevertheless, not all opportunities are currently exploited. Given innovator's benefits, consumers' welfare is maximized when the innovator is able to extract the same royalty per unit output both before and after patent's expiration. In turn, innovator's benefits depend on the legal admissibility of licensing agreements 
Hybrid Licensing of Product Innovations / 593

providing for (limited) negative fixed fees. Thus, court decisions relative to post-patent royalty levels and antitrust concerns about negative fixed fees either are not justified on efficiency grounds or, if justified as in the case of negative fees, should not lead to a per se prohibition.

We conclude by noting that, with regard to post-expiration royalties, the EU adopted an approach similar to that proposed by Judge Posner. Paragraph 159 of the Guidelines on the Application of Article 81 of the EC Treaty to Technology Transfer Agreements issued by the European Commission (2004) states: "Notwithstanding the fact that the block exemption only applies as long as the technology is valid and in force, the parties can normally agree to extend royalty obligations beyond the period of validity of the licensed intellectual property rights without falling foul of Article 81(1). Once these rights expire, third parties can legally exploit the technology in question and compete with the parties to the agreement. Such actual and potential competition will normally suffice to ensure that the obligation in question does not have appreciable anti-competitive effects." Thus, in the EU, patent licensing clauses requiring royalty payments beyond the temporal duration of the underlying patent could not be considered per se invalid by local courts. In this respect, EU regulation seems to favor efficient arrangements more as compared to US law.

\section{References}

Ayres, Ian, and Paul Klemperer. 1999. "Limiting Patentees' Market Power without Reducing Innovation Incentives: The Perverse Benefits of Uncertainty and Non-Injunctive Remedies," 97Michigan Law Review 985-1033.

Baxter, William. 1966. "Legal Restrictions on Exploitation of the Patent Monopoly: An Economic Analysis," 76 Yale Law Journal 267-370.

Bowman, Ward. 1973. Patent and Antitrust Law. A Legal and Economic Appraisal. Chicago: University of Chicago Press.

Cohen, Jerry, and Alan S. Gutterman. 1998. Trade Secrets Protection and Exploitation. Washington: The Bureau of National Affairs, Inc.

Denicolò, Vincenzo. 1996. "Patent Races and Optimal Patent Breadth and Length," 44 Journal of Industrial Economics 249-265.

Devlin, Alan. 2008. "The Stochastic Relationship between Patents and Antitrust," 4 Journal of Competition Law and Economics, doi:10.1093/joclec/nhn010.

European Commission. 2004. Guidelines on the Application of Article 81 of the EC Treaty to Technology Transfer Agreements. Official Journal of the European Union, www.epant.gr/img/x2/categories/ctg219_3_1192799410.pdf .

Gallini, Nancy. 1992. "Patent Policy and Costly Imitation," 23 RAND Journal of Economics 52-63.

DOI: $10.2202 / 1555-5879.1380$ 
Gates, Sean, and Jeny Maier. 2009. "Brulotte's Continuing Shadow over Patent Licensing," 4 Journal of Intellectual Property Law \& Practice 181-189.

Gilbert, Richard. 2006. "Competition and Innovation," 1(1) Journal of Industrial Organization Education, Article 8,__ and Carl Shapiro. 1990. "Optimal

Patent Length and Breadth," 21 RAND Journal of Economics 106-112. and 1997. "Antitrust Issues in the Licensing of Intellectual Property: The Nine No-No's Meet the Nineties," Brookings Papers on Economic Activity, Microeconomics 283-336.

Jones, Keith, Michael Whitham, and Philana Handler. 2007. "Problems with Royalty Rates, Royalty Stacking and Royalty Packing Issues," www.ipHandbook.org.

Klemperer, Paul. 1990. "How Broad Should the Scope of Patent Protection Be?" 21 RAND Journal of Economics 113-130.

Koenig, Michael. 2003. "Patent Royalties Extending Beyond Expiration: An Illogical Ban from Brulotte to Scheiber," 5 Duke Law and Technology Review 1-10.

Landes, William, and Richard Posner. 2003. The Economic Structure of Intellectual Property Law. Cambridge, Mass: Harvard University Press.

Law, Stephen. 2004. "Inter-Temporal Tie-Ins: A Case for Tying Intellectual Property through Licensing," 11 International Journal of the Economics of Business 3-26.

Lemley, Mark, and Carl Shapiro. 2005. "Probabilistic Patents," 19 Journal of Economics Perspectives 75-98.

Maurer, Stephen, and Suzanne Scotchmer. 2002. "The Independent Invention Defense in Intellectual Property," 69 Economica 535-547.

Miller, Elizabeth. 1989. "Antitrust Restrictions on Trade Secret Licensing: A Legal Review and Economic Analysis," 52 Law and Contemporary Problems 183-209.

Ottoz, Elisabetta, and Franco Cugno. 2008. "Patent-Secret Mix in Complex Product Firms," 10 American Law and Economics Review 142-158.

Shapiro, Carl. 1985. "Patent Licensing and R\&D Rivalry," 75 American Economic Review, Papers and Proceedings 25-30.

Tandon, Pankaj. 1982. "Optimal Patent with Compulsory Licensing," 90 Journal of Political Economy 470-486.

U.S. Department of Justice \& Federal Trade Commission. 2007. Antitrust Enforcement and Intellectual Property Rights: Promoting Innovation and Competition, www.usdoj.gov/atr/public/hearings/ip/222655.pdf. 